\title{
Three-dimensional Nonlinear Finite Element Analysis of Super-long Pile and Soil Interaction in Soft Soil
}

\author{
Yongquan Lu \\ Wuhan Technical College of Communications, Wuhan 430065, China
}

\begin{abstract}
In this paper, the generalized-node finite element (GFE) analysis method is presented to analyze the interaction between super-long pile and soil in soft soil. A nonlinear elastic-plastic constitutive model for concrete is employed to simulate stress-strain relation of pile shaft under the axial load. The GFE model established simulates the working properties of super-long piles, and reflects well the pile-soil slide, degradation of side friction resistance and asynchronous action between side friction resistance and pile-tip resistance. The analysis method presented in this paper is suitable for analysis of super-long piles.
\end{abstract}

Keywords-super-long pile; GFEM; nonlinear elastic-plastic constitutive model

\section{INTRODUCTION}

The super-long piles have been widely used in soft soil area, with the development of high rise buildings and advance of construction techniques, but its theoretical research on working properties falls far behind from engineering practice, in view of the complexity of pile-soil system, variability of constructing conditions, etc. make its working properties [1-10] become difficult to analyze by finite element method exactly.

The existing finite element analysis method of super-long pile and soil interaction is not well developed. As of now, all types of finite element analysis method to analyze the working properties of piles in pile and soil interaction could be defined into two sorts: one is linear analysis method, the other is nonlinear analysis method. However, a number of tests of super-long piles conducted home and abroad have indicated the nonlinear relationship of pile-soil interaction, which means over simplified analysis method like linear relation can not be suitable for super-long pile. Furthermore, the existing nonlinear analysis method established can not give consideration to the super-long pile shaft deformation under heavy axial loads. Just under the background, the analysis method presented in this paper. Through the comparison between finite element results and static load test results, it is shown that the analysis method presented in this paper is suitable for analysis of super-long piles.

\section{Generalized-NOde Finite Element MethoD}

The generalized-node finite element method (GFEM) is proposed for geotechnical study by G.H. Shi [11-13], including axial force, side friction resistance and and settlement, are obtained through the stress and displacement which are computed through the GFEM. The GFEM is a special numerical manifold method (NMM) with high degree of interpolation functions, and the traditional finite element method is a special case in GFEM.

Assuming $S_{k}$ is traditional FE space, and the sticking base function is $\left[\begin{array}{llll}N_{1} & N_{2} & \cdots & N_{n}\end{array}\right]^{T}$, then the approximately solution of displacement function can be expressed by traditional FEM:

$$
\boldsymbol{U}=\sum_{i=1}^{n} N_{i} a_{i}
$$

where $a_{i}(i=1,2, \cdots, n)$ is the vector quantities of degrees of freedom at node $i$. In elementary displacement. It subjects to the node displacement.

Making the traditional the vector quantities of degrees of freedom at node $i$ generalized, that is, each node is take for having several generalized degrees of freedom, then $a_{i}$ which denotes the traditional the vector quantities of degrees of freedom in Eq.(1) can be expressed by function of several generalized degrees of freedom,such as

$$
a_{i}=\left\{\begin{array}{l}
u_{i} \\
v_{i}
\end{array}\right\}=\sum_{j=1}^{m_{i}}\left[\begin{array}{cc}
f_{i j}(x, y) & 0 \\
0 & f_{i j}(x, y)
\end{array}\right]\left\{\begin{array}{c}
d_{i, 2 j-1} \\
d_{i, 2 j}
\end{array}\right\}
$$

Substituting Eq.(2) into Eq.(1) obtains the following a new sort of approximately expression of FEM

$$
\begin{gathered}
\boldsymbol{U}=\sum_{i=1}^{n} N_{i} \sum_{j=1}^{m_{i}}\left[\begin{array}{cc}
f_{i j}(x, y) & 0 \\
0 & f_{i j}(x, y)
\end{array}\right]\left\{\begin{array}{c}
d_{i, 2 j-1} \\
d_{i, 2 j}
\end{array}\right\} \\
=\sum_{i=1}^{n} N_{i} F_{i} D_{i}=\sum_{i=1}^{n} \underline{N}_{i} D_{i}
\end{gathered}
$$

where $D_{i}$ is the generalized vector quantities of degrees of freedom at node $i$, it is expressed by

$$
D_{i}=\left[\begin{array}{llll}
d_{i, 1} & d_{i, 2} & \cdots & d_{i, 2 m_{i}}
\end{array}\right]^{T}
$$


The node having several generalized degrees of freedom is is called the "generalized node". The $\underline{N}_{i}$ in above expression is interpolating function matrix. Because of the effect of primary base function $N_{i}$, the new base function $N_{i}$ make the compatibility obtain active satisfaction. The FE which formed by the introduced conception of generalized node is called generalized-node FEM.

\section{Elastic-Plastic Rusch Model of Super-LONG Pile}

The elastic-plastic Rusch model of concrete of pile is introduced, giving consideration to the super-long pile shaft deformation under heavy axial loads. The Rusch equation which express the stress-strain relations is as follows:

$$
\begin{gathered}
\text { when } \varepsilon \leq \varepsilon_{0}, \sigma=\sigma_{0}\left[2\left(\frac{\varepsilon}{\varepsilon_{0}}\right)-\left(\frac{\varepsilon}{\varepsilon_{0}}\right)^{2}\right] \\
\text { when } \varepsilon_{0}<\varepsilon \leq \varepsilon_{c u}, \sigma=\sigma_{0}
\end{gathered}
$$

and $\sigma_{0}$ is equal to $F_{c}$ which is the design value of axial ultimate compressive strength of concrete; $\varepsilon_{0}$ is the strain in corresponding with the peak value $\sigma_{0}$, usually between $0.0015 \sim 0.0020 ; \varepsilon_{c u}$ is the ultimate compressive strain when concrete comes into failure.

When super-long pile is under working load, the axial stress of pile usually does not exceed the compressive strength of concrete, so the parabola curve is applied to deduce the elastically nonlinear constitutive equations:

$$
E_{T}=\frac{2 \sigma_{0}}{\varepsilon_{0}} \sqrt{1-\frac{\sigma}{\sigma_{0}}} ; E_{0}=\frac{2 \sigma_{0}}{\varepsilon_{0}}
$$

where the tangent modulus of either point on the stress-strain curve is $E_{T} ; E_{0}$ is the initial tangent modulus.

\section{NUMERICAL MODELING WITH GFEM}

In order to analyze the interaction of pile-soil accurately, and to consist with the site test, step loads were used in numerical analysis. The analysis model of cast-in-place piles from real projects is shown in Fig.1.

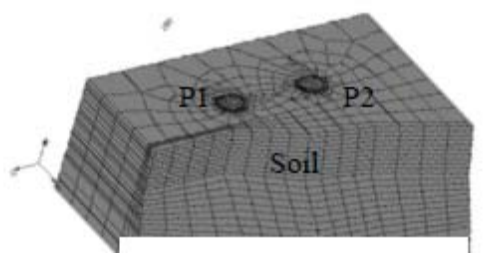

FIGURE I. GFEM MODEL

\section{GFE Modeling of Super-LONG PILEs, AND ANALysis}

The concrete types used for the load test super-long piles were C35 and C40. The length of the test piles P1 and P2 was $80 \mathrm{~m}$ and $75 \mathrm{~m}$ respectively. The diameter of the piles was $800 \mathrm{~mm}$. An enlarged pier with the diameter of $1.5 \mathrm{~m}$ and length of $2.0 \mathrm{~m}$ was used to protect the test pile head. The slow static load test was adopted in the load test. Sixteen groups of measuring deviceswere set in different depth of the pile shaft before the static load test started. The axial stress of the pile shaft, side friction resistance and the pile-tip resistance could be obtained in the process of loading.

The load-settlement curves for piles P1 and P2 are shown in Fig.2. As can be seen, the curves of test pile P1 and P2 do not have obvious turning point which show the test pile have not yet reached at the bearing capacity, and the measured laod-settlement curves are in very good agreement with the results of GFEM.

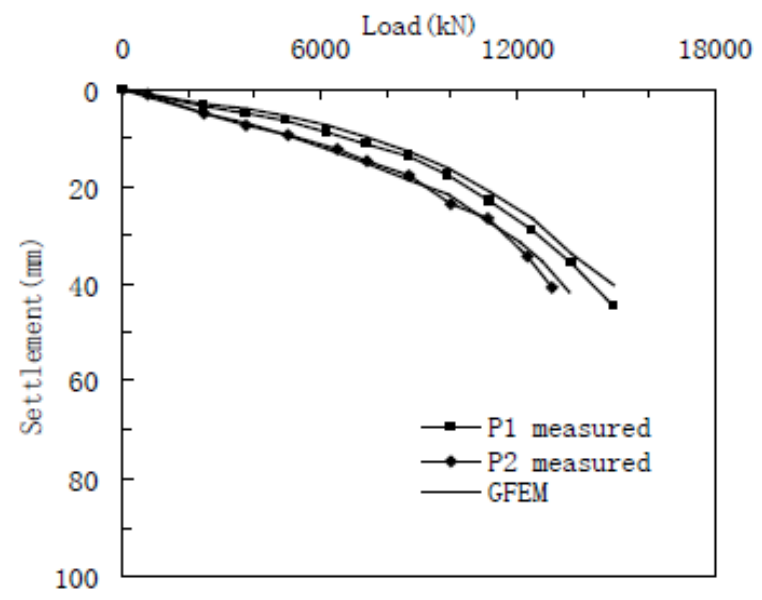

FIGURE II. LOAD-SETTLEMENT CURVES OF TEST PILES P1AND P2

Fig.3 and Fig.4 show the changing trends of axial force along the super-long pile shaft. From the Fig.3 and Fig.4, it can be seen that the axial force curves of load test piles $\mathrm{P} 1$ and $\mathrm{P} 2$ are very closed to the results obtained by generalized-node FEM, and the axial force is gradual decreasing along pile shaft, and decreasing velocity is different under different pile-head load. 


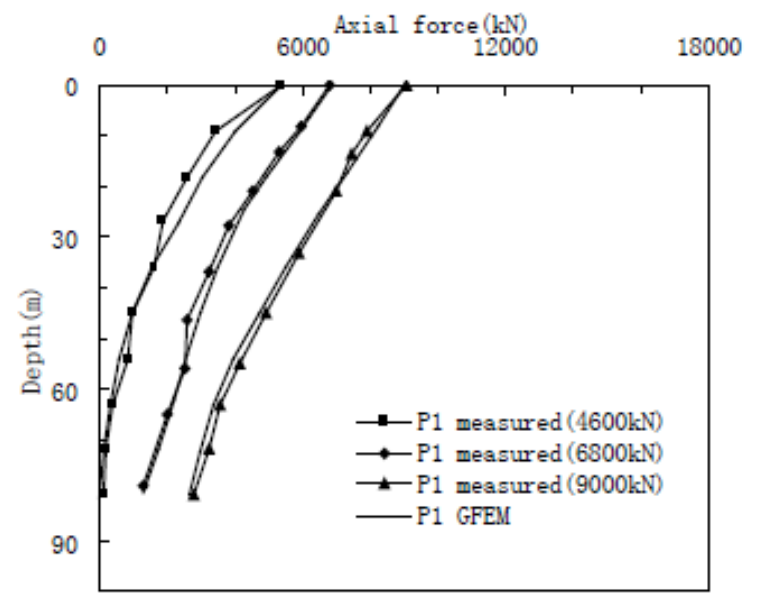

FIGURE III. AXIAL FORCE CURVES OF TEST PILE P1

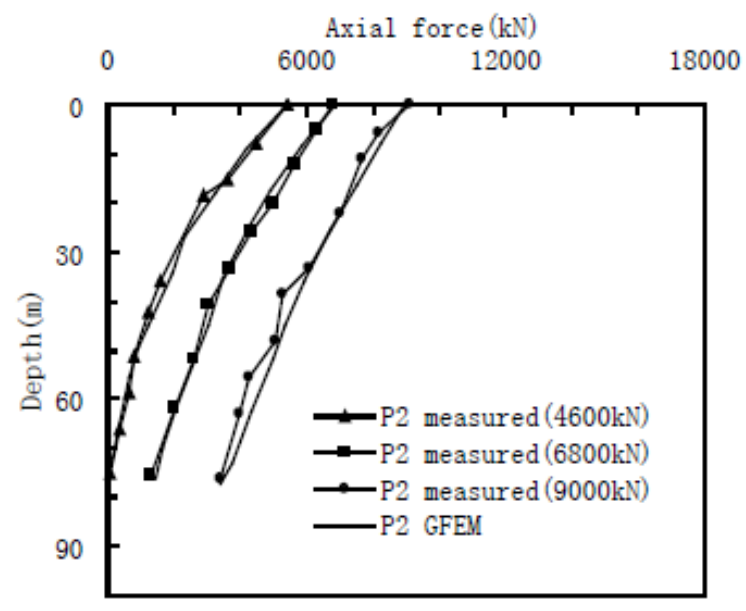

FIGURE IV. AXIAL FORCE CURVES OF TEST PILE P2

The ratio curves of pile-tip resistance $R_{b}$ to pile-head load $P_{0}$ of test piles $\mathrm{P} 1$ and $\mathrm{P} 2$ are shown in Fig.5. The super-long piles behaves as friction pile under low pile-head load. With the increase of pile-head load, the pile-tip resistance is mobilized gradually. The pile behaves as an end-bearing friction pile when pile head carry heavy load. Side friction resistance and pile-tip resistance are mobilized at the same time. This main feature for super-long piles has not been considered yet in current methods.

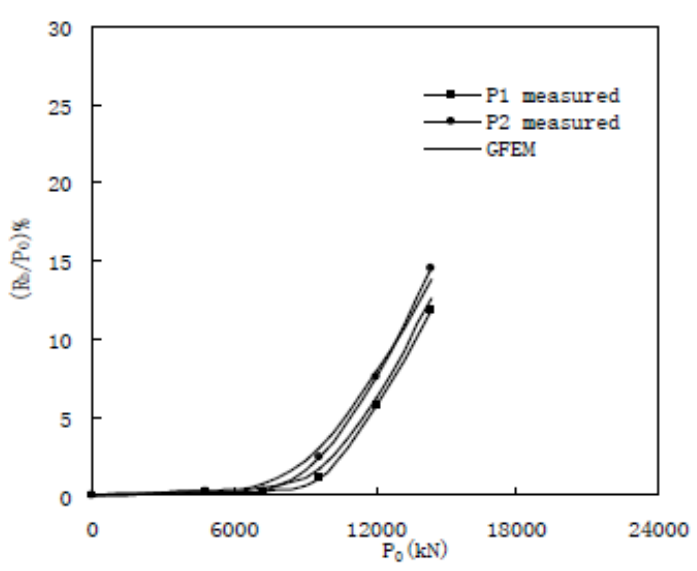

FIGURE V. RB / P0 CURVES OF TEST PILES P1 AND P2

It can be seen from Fig.6 to Fig.7 that the side friction resistance of top soil exhibits some degradation due to pile-soil slide, while side friction of the deep soil is not fully mobilized yet. When pile-head load exceeds the working load and approaches the limit load, gradated side friction resistance gradually turns to stability with the increase of pile-head load.

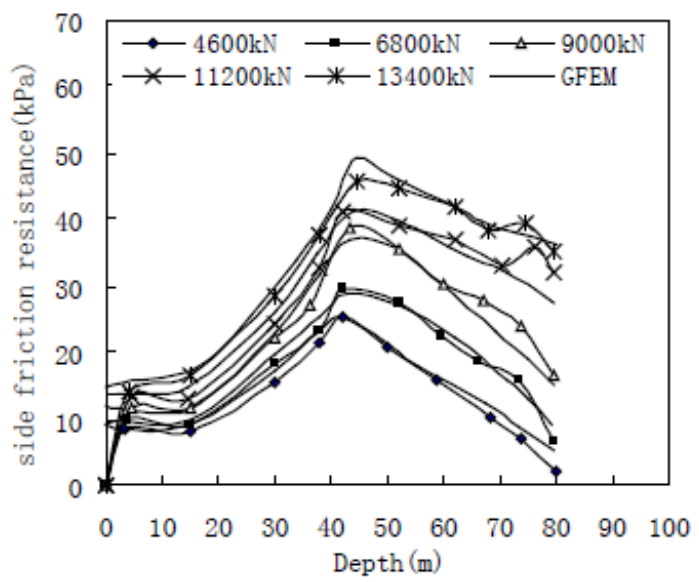

FIGURE VI. SIDE FRICTION RESISTANCE CURVES OF TEST PILE P1

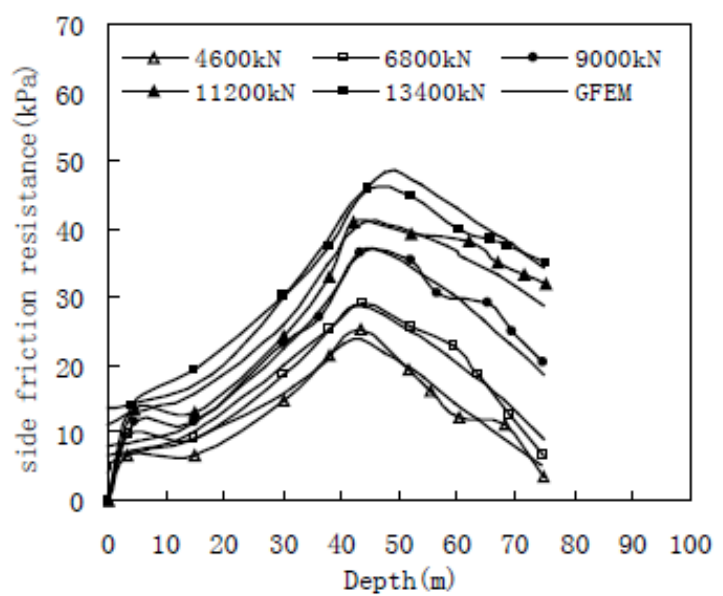

FIGURE VII. SIDE FRICTION RESISTANCE CURVES OF TEST PILE P2 


\section{CONCLUSIONS}

The GFE analysis method of super-long piles presented in this paper reflects well the working properties of piles in pile and soil interaction. The behavior of large stress of pile is described well by the nonlinear elastic-plastic constitutive models for concrete. The GFE model presented in this paper is suitable for analysis of super-long piles.

\section{REFERENCES}

[1] Huang, S.G. \& Gong, W.M. (2004). Analysis on bearing behavior of 1-stage super long-large diameter testing piles in Su-Tong bridge. J Chinese journal of rock mechanics and engineering. 3370-3375.

[2] J. Yang; L. G. Tham; P. K. K. Lee; and F. Yu. Observed Performance of Long Steel H-Piles Jacked into Sandy Soils. Journal of Geotechnical and Geoenvironmental Engineering, 2006, 132(1): 24-35

[3] Huang, S.G. \& Gong, W.M. (2006). Study on the bearing behavior of super long-large diameter piles after grouting. J Chinese Journal of Geotechnical Engineering. 113-117.

[4] Shek, M. P., Zhang, L. M., and Pang, H. W. (2006). "Setup effect in long piles in weathered soils.” Geotech. Eng., 159(3), 145-152.

[5] Lu Zhongda.(2006). Key technologies for Hangzhou bay bridge. China civil engineering journal, Vol.39(6):78-82

[6] Zhang, L. M., and Wang, H. (2007). "Development of residual forces in long driven piles in weathered soils.” J. Geotech. Geoenviron. Eng., 133(10),1216-1228.

[7] Arthur K. O. So and Charles W. W. Ng. Performance of Long-Driven H-Piles in Granitic Saprolite. Journal of Geotechnical and Geoenvironmental Engineering, 2009, 135(2): 246-258.

[8] Gao, Rui; Hu, Nian; Zhu, Bin. Experimental study and numerical analysis on bearing behaviors of super-long rock-socketed bored pile groups. Journal of Southeast University (English Edition), 2010,v 26, n 4, p 597-602.

[9] Liu, Ying ; Zhang, Li-Ming; Zheng, Gang. Finite element analysis of single piles with different lengths after grouting. Chinese Journal of Geotechnical Engineering, 2011,v 33, n SUPPL. 2, p 88-94.

[10] Zheng, Gang ; Zhang, Li-Ming; Wang, Qi. Finite element analysis on load transfer mechanism of overlength piles. Journal of Tianjin University Science and Technology, 2012,v 45, n 11, p 945-952.

[11] G.H. Shi. Modeling rock joints and blocks by manifold method.Rock Mechanics Proceedings of the 33rd U. S. Symposium, Sanata Fe, New Mexico, 1992, p.639

[12] G.H. Shi. A softening block approach to simulate excavation in jointed rocks [G]. Proceedings of the First International Forum on Discontinuous Deformation Analysis (DDA) and Simulation of Discontinuous. Media, Berkeley, California, 1996, p.52

[13] G.H. Shi. Manifold method of material analysis [G].Transactions of the Ninth Army Conference on Applied Mathematics and Computing, Minneapolis, Minnesoda, 1992, p.51. 